\title{
PENERAPAN METODE DIAGRAM PADA TRANSFORMASI GUBAHAN MASSA GO LEARN SEBAGAI TEMPAT KETIGA DI KELURAHAN DURI UTARA
}

\author{
Adi Wijaya ${ }^{1)}$, Suwardana Winata ${ }^{2)}$ \\ 1)Program Studi S1 Arsitektur, Fakultas Teknik, Universitas Tarumanagara, adi.wijaya.1010@gmail.com \\ 2)Program Studi S1 Arsitektur, Fakultas Teknik, Universitas Tarumanagara, danarsitek@gmail.com \\ Masuk: 14-07-2020, revisi: 01-08-2020, diterima untuk diterbitkan: 24-09-2020
}

\begin{abstract}
Abstrak
Definisi keterikatan adalah disaat manusia dapat berkumpul bersama, mengejar tujuan yang sama, sekaligus berinteraksi satu sama lain saat prosesnya. Mungkin begitulah third place diciptakan, dimana tempatnya melihat kembali karakter kawasannya, sehingga program yang dihadirkan tepat guna. Go Learn adalah sebuah wadah edukasi yang berlokasi di Duri Utara. Melihat karakter kawasannya yang didominasi oleh fasilitas pendidikan formal, sebuah tempat dengan edukasi informal sebagai program utamanya dijamin dapat meningkatkan antusias masyarakat sekitar karena akan menjadi tempat melepaskan diri dari kesibukan normalitas. Aktivitasnya berbasis kuliner, musik dan kerajinan yang didapatkan oleh analisis konteks sekitar. Dekatnya dengan Krendang memicu untuk aktivitas kuliner yang bukan menjadi lawan tetapi sebagai pendukung utama dengan menyediakan kelas memasak untuk meningkatkan kemampuan masyarakatnya. Musik yang menjadi kegemaran nomor satu manusia sejak dulu apalagi anak-anak, mendukung penduduk yang mayoritasnya adalah generasi muda. Edukasi musik diharapkan menjadi pengikat antar kalangan sekaligus menghidupkan kawasannya dengan pertunjukan yang mereka bawa sendiri. Kain perca, menjadi salah satu industri terbanyak di kawasan Duri Utara yang biasanya dijual secara mentah. Dengan adanya edukasi kerajinan untuk mengolah kain tersebut, ekonomi mereka diharapkan meningkat seiringnya dengan kemampuan mereka terhadap kerajinan. Hadirnya Go Learn pada Duri Utara, dengan transformasi massa yand didapat oleh diagram musik, diharapkan mengumpulkan masyarakatnya bersama dengan tujuan untuk meningkatkan kemampuan mereka serta melepaskan diri sejenak. Interaksi satu sama lain yang dilakukan selama prosesnya nanti akan mendekatkan mereka secara komunitas dan kekeluargaan.
\end{abstract}

Kata kunci: edukasi; kerajinan; kuliner; musik; ruang ketiga

\begin{abstract}
The definition of togetherness is when human can come together, pursuing the same goals, and interact with each other during the process. Maybe that's how a Third place is created, where the project trace back at the character of the surroundings, so that the planned program is certainly appropriate. Go Learn is an educational place in Duri Utara. Looking at the character of the region which is dominated by formal educational facilities, a place with informal education as its main program is guaranteed to increase the enthusiasm of the surrounding comimunity because it will become a place to escape from the bustle of normality. It's main programs are based on culinary, music and craft which are obtained by analyzing the surrounding context. Located near Krendang triggers culinary activities on the site that are meant not to oppse but as a major support by providing cooking classes to improve the skills of its people. Music has become the number one passion of humans, especially for children, suitable for the majority of the population which are young adults. Music education is expected to gather groups of different backgrounds and at the same time enliven the area with performances that is played by themselves. Patchwork fabric, being one of the most common industries in Duri Utara region, and are usually sold raw. With craft education to process the fabrics, their economy is expected to grow along their skills on hand crafting. The presence of Go Learn in Duri Utara, with its form generated from music diagramss, is expected to gather the community together with the aim to improve their abilities and escape for a moment. Interaction with each other that is carried out during the process will bring them closer as a community and kinship.
\end{abstract}

Keywords: craft; culinary; education; music; third place 


\section{PENDAHULUAN}

Pada bukunya Oldenburg (1989) yang berjudul "The Great Good Place" menyatakan bahwa dalam kehidupan manusia sehari - harinya, harus terjadi keseimbangan di antara tiga lingkup. Lingkup pertama bersifat domestik, lingkup kedua bersifat produktif dan lingkup ketiga meliputi sosial yang berlandas komunitas. Duri Utara adalah suatu kawasan dengan heterogenitas tinggi dan sibuk dengan rutinitas sehari - hari yang begitu padatnya, memiliki perumahan yang padat dengan jalan - jalan kecil sebagai penghubung dan beroperasinya salah satu stasiun transit terbesar di Jakarta. Dengan deskripsi singkat itu rasanya ada yang hilang kalau ditinjau dari buku Ray Oldenburg di atas. Tingkat sosialisasi masyarakat di kawasan Duri Utara rendah dengan kesibukan mereka sehari - hari, salah satunya dikarenakan oleh tidak adanya wadah untuk mereka bersosialisasi. Duri Utara sendiri adalah kawasan dengan permukiman padat dan tidak memiliki ruang publik sama sekali. Third place hadir ke dalam Duri Utara dengan tujuan memenuhi interaksi sosial yang dibutuhkan oleh manusia selaku makhluk sosial serta membantu meningkatkan kualitas hidup masyarakat sekitarnya. Dengan penduduk yang didominasi oleh anak - anak usia belajar, dibutuhkan Third place yang tidak hanya berfungsi untuk mereka berinteraksi, namun membekali diri mereka untuk menghadapi kehidupan dewasa nantinya. Third place yang akan dirancang dengan sarana edukasi yang menggabungkan masyarakat dari semua kalangan untuk tujuan yang lebih baik yaitu mendapatkan ilmu. IImu yang didapat bersifat di luar pendidikan formal dan merupakan tambahan untuk keterampilan masing - masing individu agar kawasan Duri Utara memiliki sifat yang ramai masyarakatnya, maju penduduknya. (Kemendikbud RI, 2020) Kata "Go" sendiri memiliki arti pergi atau berpindah dari suatu tempat ke tempat lainnya. Dengan harapan mereka dapat berkembang dengan pembelajaran yang didapat di Third place ini. Selain ilmu yang didapat, mereka juga diharapkan untuk mendapat interaksi sosial fisik agar kebutuhan sosialisasi mereka terpenuhi.

Dari pembahasan tersebut, terdapat rumusan masalah utama yaitu bagaimana sebuah metode yang berasal dari diagram diterapkan kedalam bangunan untuk membuat ruang - ruang aktivitas third place di dalamnya. Serta bagaimana merubah ruang - ruang negatif yang dihasilkan agar dapat tetap berfungsi tanpa merubah drastis bentukan awal yang didapat. Dengan terbangunnya Third place pada suatu kawasan akan memberikan sisi positif bagi para masyarakatnya. Mereka akan lebih sering berinteraksi satu sama lain dan meningkatkan hubungan mereka. Selain faktor sosial, third place juga ditujukan untuk meningkatkan kualitas hidup masyarakat terutama pada sekitarnya, dalam proyek ini dimaksud dengan bidang edukasi informal. Perekonomian bagi masyarakat sekitar juga akan meningkat dengan adanya crowd yang terkumpul di suatu wilayah. Manfaat pada sektor kota ialah menjadi pusat destinasi baru dalam kota yang kemungkinan besar mayoritas targetnya adalah pekerja muda dan pelajar. Karena berada di dekat pusat transit masyarakat kota, destinasi akan lebih mudah dicapai dan meningkatkan minat masyarakat untuk datang. Selain itu juga meningkatkan kepekaan pemerintah akan kebutuhan third place pada kawasan - kawasan lain dan mendorong mereka untuk menghadirkan third place di tempat lainnya. Manfaat untuk masa depan adalah dengan menjadikan Jakarta sebagai kota yang memiliki interaksi lebih erat pada masyarakatnya dan berkelanjutan dengan menciptakan program yang bertahan hingga tahun tahun ke depan dan bersifat adaptif akan perubahan yang mungkin nanti terjadi.

Faktor lainnya adalah Sustainable Development Goals (SDGs) yang dibuat oleh Perserikatan Bangsa - Bangsa untuk menjadikan dunia lebih berkelanjutan. Target - target ini diperkirakan akan terlaksana pada tahun 2030 dan ada perbaikan di tahun 2020 mendatang. Pada proyek ini, tidak semua SDG dipenuhi, namun ada beberapa yang dapat ditekankan pada proyek third place kali ini yaitu Good Health and Well Being, Quality Education, Gender Equality, Decent Work and Economic Growth, Reduced Inequalities dan Sustainable Cities and Communities. 


\section{KAJIAN LITERATUR}

\section{Third Place}

Pada Buku The Great Good Place yang ditulis oleh Oldenburg (1989), dijelaskan bahwa sebuah Third Place ada tempat informal untuk berkumpul para masyarakat yang terletak antara rumah dan tempat kerjanya. Dalam buku tersebut juga dipaparkan karakteristik mengenai third place. "In community building, the third place is the social surroundings separate from the two usual social environments of home ("first place") and the workplace ("second place"). Examples of third places would be environments such as churches, cafes, clubs, public libraries, or parks. In his influential book The Great Good Place, Ray Oldenburg $(1989,1991)$ argues that third places are important for civil society, democracy, civic engagement, and establishing feelings of a sense of place." (Wikipedia, 20 Januari 2020).

Sebuah third place harus Neutral dengan arti sebuah tempat harus dapat mengundang dan menjadi titik kumpul bagi para masyarakatnya secara bebas. Ciri kedua adalah Level dimana tempat tersebut tidak membedakan latar belakang masing - masing masyarakat, namun membuat mereka semua setara. Ciri ketiga adalah Conversation dimana komunikasi menjadi aktivitas utama pada third place. Ciri keempat adalah Accessibility yang berarti pencapaiannya mudah dan beroperasi kapan saja karna menyesuaikan dengan seluruh masyarakat sekitarnya. Ciri kelima ada Regulars dimana masyarakat yang sering datang ketempat tersebut adalah masyarakat sekitar kawasannya. Ciri keenam adalah Low Profile dimana tempat tersebut melengkapi konteks kawasannya dengan menjadi ruang aktif komunitas. Ciri ketujuh adalah Playful yang merupakan suasana di sebuah third place (Oldenburg, 1997). Karakteristik tersebut nantinya akan di kaitkan dengan proyek yang dapat berupa bentukan maupun fungsi dari bangunan.

\section{Abraham Maslow, "A Theory of Human Motivation"}

Abraham Maslow adalah seorang psikolog Amerika yang membuat teori mengenai kebutuhan manusia. Dalam teorinya, dia membagi kedalam 5 tahap dimana untuk mencapai tingkat selanjutnya, tingkatan sebelumnya harus dipenuhi terlebih dahulu. Manusia adalah makhluk yang rakus dan akan terus membutuhkan sesuatu untuk melengkapi hidupnya, sampai di tingkat puncak yaitu tingkat kelima. (Maslow, 1943) "It is quite true that man lives by bread alone - when there is no bread. But what happens to man's desires when there is plenty of bread and when his belly is chronically filled? At once other (and "higher") needs emerge and these, rather than physiological hungers, dominate the organism. And when these in turn are satisfied, again new (and still "higher") needs emerge and so on. This is what we mean by saying that the basic human needs are organized into a hierarchy of relative prepotency" (Maslow, 1943, p. 375).

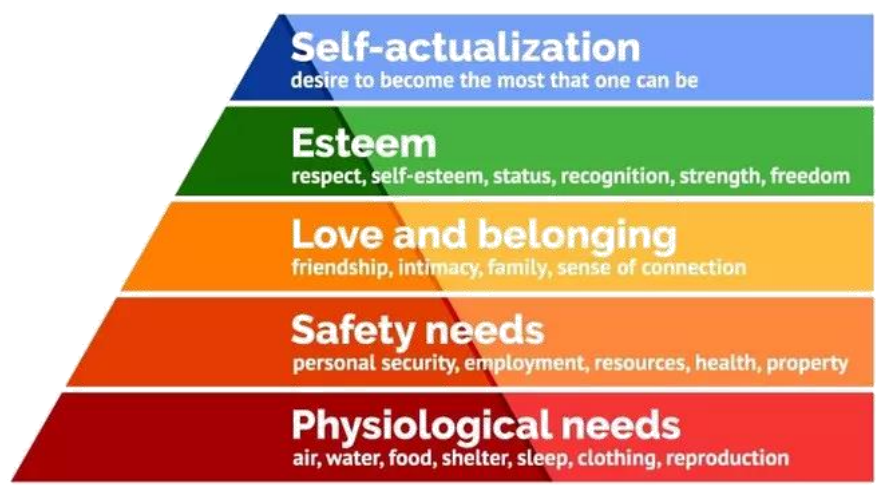

Gambar 1. Hierarchy of Needs versi Abraham Maslow Sumber: simplypsychology.org, Januari 2020 
Pada tingkatan pertama tentang kebutuhan fisiologis seperti makan, minum, tidur, udara dan lainnya, ini adalah kualitas yang didapatkan di rumah kita atau Home atau yang lebih kita kenal dengan first place. Pada tingkatan kedua ketika tahap pertama sudah terpenuhi, kita mencari pekerjaan, properti, hal hal lain untuk memberikan kita rasa aman dan terjamin, ini yang dikaitkan dengan pekerjaan kita atau second place. Pada tingkatan ketiga ketika kita sudah merasa aman dan nyaman, kita mencari interaksi sosial kepada sesame manusia, bisa itu sahabat, keluarga, pacar atau lainnya yang memicu koneksi. Ini terkait dengan adanya Third place di kehidupan kita. Pada tingkatan keempat ketika interaksi sosial sudah terpenuhi, maka manusia akan mencari kebutuhan yang membuat mereka diakui oleh orang lain. Kebutuhan ini erat kaitannya dengan status, percaya diri dan rasa hormat. Pada tingkatan terakhir, tingkat kelima ketika manusia sudah memenuhi kebutuhan - kebutuhan sebelumnya, maka manusia akan mencari sesuatu yang lebih tinggi lagi karena tidak merasa puas, biasanya dikaitkan dengan hal yang luar biasa seperti rohani, ketuhanan bahkan pengalaman - pengalaman yang tidak terlupakan (Maslow, 1943).

Dari pernyataan diatas, dapat disimpulkan bahwa ada keterkaitan teori Maslow dengan kehidupan sehari - hari kita dimana kebutuhan didefinisikan per tingkatannya. Kaitan "place" dengan lapisan kebutuhan itu memiliki fungsi yang seragam, maka dari itu desain Third place menurut saya harus memperhatikan friendship, intimacy, family dan sense of connection untuk benar - benar menjadikan sebuah proyek Third place dapat memenuhi kebutuhan manusia di tingkat ketiga. Hal yang diperhatikan tersebut nantinya akan menjadi kriteria desain pada proyek terkait.

\section{Teori Programming}

Pada bukunya Pena (2001) yang berjudul "Problem Seeking", dia memaparkan sebuah cara untuk mendapatkan program bangunan. Berbeda dengan desain dimana tujuannya adalah memecahkan masalah, program baginya adalah cara untuk mencari masalah tersebut yangn nantinya akan dipecahkan oleh desain. "Good buildings don't just happen. They are planned to look good and perform well, and come about when good architects and good clients join in thoughtful, cooperative effort. Programming the requirements of a proposed building is the architect's first task, often the most important." (Pena, 2001)

Terdapat 5 tahap dalam pencarian masalah menurut Pena yaitu:

a. Establishing Goals

b. Collect and Analyze Facts

c. Uncover and Test Concepts

d. Determine Needs

e. Stating the Problem

Dari kelima tahapan tersebut, 3 tahap pertama mengacu kepada pengumpulan data dan tahap ke 4 adalah di mana keputusan dibuat. Nantinya akan ada 4 konsiderasi mengenai masing masing tahapan dengan 3 sub-konsiderasi dibawahnya. Berikut adalah konsiderasinya:

Function

People

Activities

Relationship

Form

Site

Environment

Quality
Economy

Initial Budget

Operating Cost

Life Cycle Cost

Time

Past

Present

Future 
Untuk melakukan metode ini, langkah tersebut dikaitkan dengan konsiderasi yang ada dalam sebuah table yang berbentuk seperti ini:

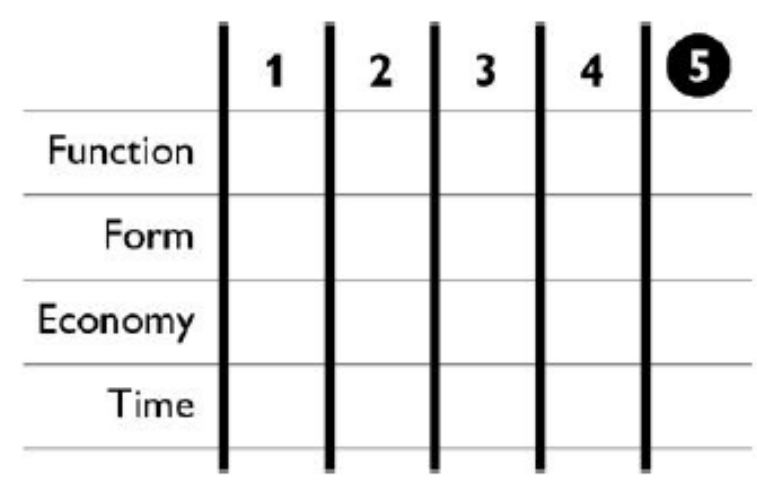

Gambar 2. Format Proses Pencarian Problem Sumber: Pena, Problem Seeking, 2001

\section{Aktivitas di Waktu Luang}

Jayson DeMers pemilik Audience Bloom dalam salah satu artikelnya pernah menuliskan bahwa ada kebiasaan - kebiasaan yang dilakukan oleh orang - orang untuk mengisi waktu luangnya agar dapat mengembangkan dirinya. Aktivitas tersebut beragam fungsinya mulai dari menambah pengalaman, koneksi sampai dengan ilmu atau sekedar untuk kepentingan jasmani. Aktivitas tersebut ialah olahraga, membaca, mengikuti kelas, kerja bakti, bersosialisasi, melakukan hobi dan menghabiskan waktu dengan keluarga maupun teman. (inc.com, Februari 2020). Aktivitas - aktivitas tersebut nantinya akan dipilih berdasarkan kecocokan dengan proyek yang dimana harus sesuai dengan karakter Third Place nantinya. Aktivitasnya harus dapat mengumpulkan banyak kalangan masyarakat yang pastinya berguna pula bagi kawasan Duri Utara. Aktivitasnya juga harus menjadi suatu aktivitas baru sehingga peran Third Place sebagai penunjang kawasan tetap dipertahankan.

\section{Minat paling Populer}

Sebuah riset oleh Alaa Hassan, seorang ahli e-commerce membuat sebuah riset yang didasari oleh observasinya tentang minat yang dimiliki oleh manusia dan menemukan minat - minat paling populer. Minat - minat tersebut dapat menjadi cabang - cabang seperti contoh ketika orang mempunyai minat di bidang musik, orang tersebut dapat saja senang mendengarkan musik tetapi tidak untuk memainkannya. Keenam minat tersebut adalah musik, makanan, olahraga, kerajinan, binatang dan jalan - jalan. (alaahassan.com, Januari 2020). Minat - minat tersebut nantinya akan dipilih bedasarkan karakter Duri Utara melalui analisis kawasan sehingga dapat muncul minat mana yang paling sesuai. Minat - minat itu nantinya akan digabungkan dengan literatur aktivitas di waktu luang agar menimbulkan program yang sesuai.

\section{METODE}

\section{Metode Penyusunan Program Aktivitas}

Program yang dicari tentunya adalah yang berhubungan dengan third place, maka dari itu teori Ray Oldenburg mengenai karakteristik sebuah third place akan dijadikan kriteria utama untuk mencari permasalahan. Berikut adalah tabel program yang tercipta dari analisis: 
Tabel 1. Analisis Problem Karakter Neutral

\begin{tabular}{l|l|l|l|}
\hline Neutral & \multicolumn{4}{l|}{ Facts } & Concepts \\
\hline Function & $\begin{array}{l}\text {-Komunitas sekitar } \\
\text { sebagai user utama } \\
\text {-Semua orang dapat } \\
\text { masuk }\end{array}$ & $\begin{array}{l}\text {-Peak hour sangatlah } \\
\text { padat dikarenakan } \\
\text { oleh adanya stasiun }\end{array}$ & $\begin{array}{l}\text {-Dibagi kedalam kelompok } \\
\text { usia dan komunitas untuk } \\
\text { menghasilkan aktivitasnya. }\end{array}$ \\
\hline Form & - & - & - \\
\hline Economy & - & - & - \\
\hline Time & - & - & - \\
\hline
\end{tabular}

Sumber : Penulis, 2020

Tabel 2. Analisis Problem Karakter Level

\begin{tabular}{|c|c|c|c|}
\hline & Goals & Facts & Concepts \\
\hline Function & $\begin{array}{l}\text {-Semua orang dapat } \\
\text { masuk }\end{array}$ & $\begin{array}{l}\text {-Banyak sekolah } \\
\text { dengan umur pelajar } \\
\text { (4-15 tahun) } \\
\text {-Banyak tempat kursus } \\
\text {-Orang tua bekerja } \\
\text { sebagai penjaga toko } \\
\text { dan buruh pabrik }\end{array}$ & $\begin{array}{l}\text {-Dibagi kedalam kelompok } \\
\text { usia dan komunitas untuk } \\
\text { menghasilkan aktivitasnya. } \\
\text {-Menggabungkan semua } \\
\text { orang dengan program yang } \\
\text { sama }\end{array}$ \\
\hline Form & - & - & - \\
\hline Economy & $\begin{array}{l}\text {-Menaikkan } \\
\text { perekonomian warga }\end{array}$ & $\begin{array}{l}\text {-Mayoritas menengah } \\
\text { ke bawah }\end{array}$ & $\begin{array}{l}\text {-Dikelola oleh warga } \\
\text { sekitarnya }\end{array}$ \\
\hline Time & - & - & \\
\hline
\end{tabular}

Sumber : Penulis, 2020

Tabel 3. Analisis Problem Karakter Conversation

\begin{tabular}{|c|c|c|c|}
\hline \multicolumn{4}{|c|}{ Conversation } \\
\hline & Goals & Facts & Concepts \\
\hline Function & $\begin{array}{l}\text {-Tempat sosial bagi } \\
\text { masyarakat }\end{array}$ & $\begin{array}{lr}\text {-RPTRA } & \text { merupakan } \\
\text { tempat } & \text { publik } \\
\text { terdekat } & \\
\end{array}$ & $\begin{array}{l}\text {-Menggabungkan semua } \\
\text { orang dengan program yang } \\
\text { sama }\end{array}$ \\
\hline Form & $\begin{array}{l}\text {-Meningkatkan } \\
\text { kualitas sosial }\end{array}$ & $\begin{array}{l}\text {-Dikelilingi oleh } \\
\text { perumahan, } \\
\text { pertokoan dan ruko }\end{array}$ & $\begin{array}{l}\text {-Pendidikan bagi semua } \\
\text { kalangan masyarakat }\end{array}$ \\
\hline Economy & - & - & - \\
\hline Time & - & - & - \\
\hline
\end{tabular}

Sumber : Penulis, 2020 
Tabel 4. Analisis Problem Karakter Accessibility

\begin{tabular}{|c|c|c|c|}
\hline \multicolumn{4}{|c|}{ Accessibility } \\
\hline & Goals & Facts & Concepts \\
\hline Function & -Walkable & $\begin{array}{lr}\text {-RPTRA } & \text { merupakan } \\
\text { tempat } & \text { publik } \\
\text { terdekat } & \end{array}$ & $\begin{array}{l}\text {-Jadwal leisure dilakukan } \\
\text { pada peak hour }\end{array}$ \\
\hline Form & $\begin{array}{l}\text {-Mudah dijangkau } \\
\text { oleh semua orang }\end{array}$ & $\begin{array}{lr}\text {-Tidak adanya } & \text { lahan } \\
\text { kosong } & \text { untuk } \\
\text { pembangunan } & \text { di } \\
\text { tengah kawasan } & \end{array}$ & $\begin{array}{l}\text {-Kawasan ramah pejalan } \\
\text { kaki } \\
\text {-Terbuka di } 4 \text { sisi tapak } \\
\text {-Membeli tanah di tengah } \\
\text { kawasan }\end{array}$ \\
\hline Economy & - & - & - \\
\hline Time & - & - & - \\
\hline
\end{tabular}

Sumber : Penulis, 2020

Tabel 5. Analisis Problem Karakter Regular

\begin{tabular}{|c|c|c|c|}
\hline & Goals & Facts & Concepts \\
\hline Function & $\begin{array}{l}\text {-Meningkatkan } \\
\text { efisiensi }\end{array}$ & $\begin{array}{l}\text {-RPTRA merupakan } \\
\text { tempat publik } \\
\text { terdekat } \\
\text { - Banyak sekolah } \\
\text { dengan umur pelajar } \\
\text { (4-15 tahun) } \\
\text {-Banyak tempat kursus } \\
\text {-Orang tua bekerja } \\
\text { sebagai penjaga toko } \\
\text { dan buruh pabrik }\end{array}$ & $\begin{array}{l}\text {-Dibagi kedalam kelompok } \\
\text { usia dan komunitas untuk } \\
\text { menghasilkan aktivitasnya. }\end{array}$ \\
\hline Form & $\begin{array}{l}\text {-Meningkatkan } \\
\text { komunitas per } \\
\text { individunya } \\
\text {-Derajatnya dinaikkan } \\
\text {-Kualitas hidupnya } \\
\text { naik }\end{array}$ & $\begin{array}{l}\text {-Dikelilingi oleh } \\
\text { perumahan, } \\
\text { pertokoan dan ruko }\end{array}$ & $\begin{array}{l}\text {-Pendidikan bagi semua } \\
\text { kalangan masyarakat }\end{array}$ \\
\hline Economy & $\begin{array}{l}\text {-Jadi penghasilan } \\
\text { tambahan }\end{array}$ & $\begin{array}{l}\text {-Kendaraan utamanya } \\
\text { adalah sepeda motor } \\
\text {-Banyak penjual } \\
\text { gerobak }\end{array}$ & $\begin{array}{l}\text {-Diadakan tempat sewa } \\
\text {-Ada aktivitas berbayarnya }\end{array}$ \\
\hline Time & - & - & - \\
\hline
\end{tabular}

Sumber : Penulis, 2020

Tabel 6. Analisis Low Profile

\begin{tabular}{|c|c|c|c|}
\hline & Goals & Facts & Concepts \\
\hline Function & $\begin{array}{l}\text {-Third place untuk } \\
\text { kawasan sekitar }\end{array}$ & $\begin{array}{l}\text {-Peak hour sangatlah } \\
\text { padat dikarenakan } \\
\text { oleh adanya stasiun } \\
\text {-Banyak gang kecil } \\
\text {-Banyak sarana ibadah }\end{array}$ & $\begin{array}{l}\text {-Jadwal leisure dilakukan } \\
\text { pada peak hour }\end{array}$ \\
\hline Form & -Responsif terhadap & -Iklim tropis & -Mengacu kepada sekolah \\
\hline
\end{tabular}




\begin{tabular}{|l|l|lr|lr}
\hline & tapak & $\begin{array}{l}\text {-Banyak rumah }- \\
\text { rumah dempet di } \\
\text { sekitar kawasan }\end{array}$ & $\begin{array}{l}\text { sebagai } \\
\text { mayoritas }\end{array}$ & komunitas \\
\hline Economy & $\begin{array}{l}\text {-Dibiayai oleh } \\
\text { pemerintah sebagai } \\
\text { modal utama } \\
\text {-Mandiri operasional }\end{array}$ & $\begin{array}{l}\text {-Target market datang } \\
\text { dari segala macam } \\
\text { arah }\end{array}$ & $\begin{array}{l}\text {-Memasukkan penjual dari } \\
\text { luar ke dalam proyek }\end{array}$ \\
\hline Time & $\begin{array}{l}\text {-Tidak meninggalkan } \\
\text { budaya yang ada }\end{array}$ & $\begin{array}{l}\text {-Dominan } \\
\text { perumahan }\end{array}$ & area & $\begin{array}{l}\text {-Fungsi lama akan tetap } \\
\text { dijaga }\end{array}$ \\
\hline
\end{tabular}

Sumber : Penulis, 2020

Tabel 7. Analisis Problem Karakter Playful

\begin{tabular}{|c|c|c|c|}
\hline & Goals & Facts & Concepts \\
\hline Function & -Sebagai short-escape & $\begin{array}{lr}\text {-RPTRA } & \text { merupakan } \\
\text { tempat } & \text { publik } \\
\text { terdekat } & \end{array}$ & $\begin{array}{l}\text {-Jadwal leisure dilakukan } \\
\text { pada peak hour }\end{array}$ \\
\hline Form & - & - & - \\
\hline Economy & - & - & - \\
\hline Time & $\begin{array}{l}\text {-Bisa merubah } \\
\text { aktifitas sesuai dengan } \\
\text { perkembangan }\end{array}$ & $\begin{array}{l}\text {-Program disekitar } \\
\text { kawasan tetap dan } \\
\text { tidak berubah }\end{array}$ & $\begin{array}{l}\text {-Adaptasi } \\
\text { perubahan }\end{array}$ \\
\hline
\end{tabular}

Sumber : Penulis, 2020

Bedasarkan tabel - tabel di atas, needs atau kebutuhan proyek ini dibagi ke dalam 4 konsiderasi ialah:

a. Function Needs

Aktivitas beragam di setiap jam nya agar dapat dipakai hampir setiap waktunya; Selain berkumpul dan bersosialisasi, aktivitas pembelajaran dapat menjadi aktivitas utama

b. Form Needs

Tapak dengan akses ke segala arah; Dekat dengan sekolah; Tidak berisik; Berada pada jalan lingkungan I; Bisa diakses dengan mudah

c. Economy Needs

Ruang-ruang komersial di tengah-tengah third place

d. Time Needs

Diagram aktivitas di third place nantinya

\section{Program Bangunan}

Dengan terteranya needs dari proyek, maka selanjutnya problem akan muncul dengan berupa program dari bangunan itu sendiri. Dilansir dari Jayson DeMers (inc.com, Februari 2020), terdapat 6 aktivitas di mana orang dengan rutinitas tinggi dapat berkumpul dan bersosialisasi dengan mengembangkan diri mereka, yaitu exercise, music, volunteer, culinary, craft dan travelling. Dari keenam aktivitas tersebut, dipilihlah program yang cocok untuk tapak yang berlokasi di tengah - tengah Duri Utara. Program pertama adalah kuliner, karena berbatasan dengan Kelurahan Krendang yang dikenal dengan banyaknya kuliner pada jalan utamanya. Program yang nanti muncul bukanlah sebuah pusat kuliner, tetapi mendukung kuliner yang ada di Krendang lewat sarana edukasi kuliner yang mampu meningkatkan kemampuan memasak mereka. Tidak hanya itu, ibu rumah tangga dan anak-anak biasanya sangat dekat dengan aktivitas memasak yang nantinya kegiatan ini akan dapat menyatukan mereka di dalam sebuah kelas. 
Musik merupakan minat nomor satu di dunia (alaahassan.com, Januari 2020) dan semua umur dapat menikmatinya. Sebuah tempat yang menghadirkan edukasi informal tidaklah lengkap tanpa edukasi musik karena sangat diminati oleh orang banyak dan beragam latar bekalang pula. Salah satu faktor keberhasilannya third place adalah mampunya sebuah tempat menjadi tempat kumpulnya orang banyak maupun dari kalangan apapun. Lokasi Duri Utara yang banyak terdapat buruh industri tidak melupakan kalangan masyarakat menengah kebawah tersebut. Banyaknya industri kain perca di sekitar kawasan yang biasanya mereka hanya jual secara mentah, memicu program lain yaitu kerajinan yang terbuat dari kain perca yang nantinya dapat dijadikan alat keperluan rumah tangga seperti sprei, sarung, tatak meja, bahkan furniture seperti sofa dan bantal. Ketiga program utama tersebut, nantinya akan memicu aktivitas lain sesuai dengan kebutuhan yang ada pada tapak. Penjabaran aktivitas pada jam - jam tertentu menjadi salah satu faktor agar bangunan dapat terus hidup pada saat jam produktif. Contoh subprogram yang dapat muncul nantinya adalah seperti panggung hiburan, area makan maupun galeri untuk memamerkan kerajinan dari kelas kain perca.

\section{Metode Perancangan Massa}

Arsitek dalam merancang disadari atau tanpa disadari selalu menggunakan metode dalam setiap rancangannya. Beberapa metode baru saja ditemukan akhir - akhir ini dan beberapa lainnya sudah menjadi hukum wajib dari ratusan tahun yang lalu (Jormakka, 2003). Dalam buku Basic Design Methods oleh Kari Jormakka terdapat beberapa metode yang dipaparkan dengan contoh penggunaannya serta kelebihan dan kekurangan pada metode - metode tersebut. Pada proyek kali ini, dipilih metode Music and Mathematics as Models dengan alasan bahwa program yang diusung harus memiliki kaitan dengan metode bentuk yang digunakan. Jadi di dalam bangunan tersebut, tidak hanya aktivitasnya yang dirasakan, namun bangunan sendirinya pun dapat mencerminkan aktivitas tersbut.

\section{DISKUSI DAN HASIL}

\section{Proses Transformasi}

Musik yang dipilih tidak serta - merta musik apa saja. Lagunya harus memiliki kriteria yaitu harus identik dengan kawasannya, bersifat edukasi, dapat menceritakan tentang kuliner atau kerajinan dan memiliki dapat diterjemahkan menjadi not balok karena nantinya transformasi akan menggunakan not - not tersebut.Terpilihlah lagu Wajib Belajar, sebuah lagu yang diciptakan oleh Restu Narwan yang menceritakan tentang dorongan untuk belajar agar dapat membangun bangsa. Not balok lagu tersebut kemudian mulai ditransformasikan menjadi garis - garis diagram yang nantinya akan dipakai untuk menjadi dasar pembuatan bidang - bidang.

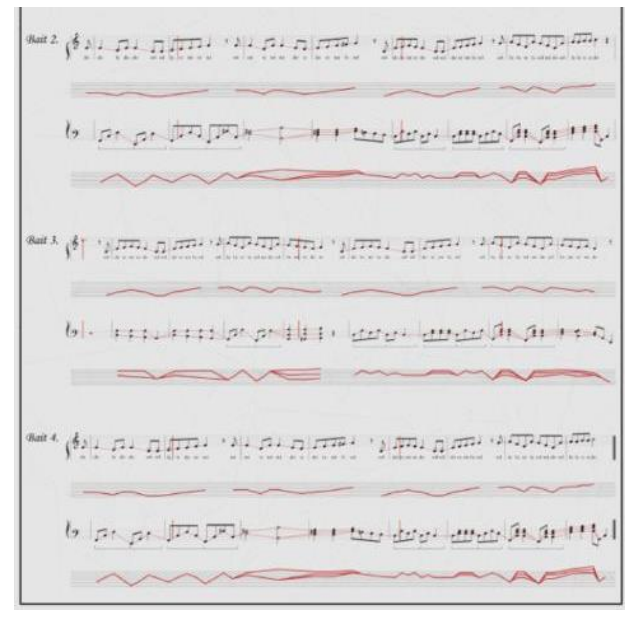

Gambar 3. Perubahan Not ke Diagram Sumber: penulis, 2020 
Transformasi dilakukan pada kedua kunci not yaitu kunci $\mathrm{G}$ dan kunci $\mathrm{F}$ yang melambangkan melodi dan ritme. Keduanya berjalan seiringan agar menjadikan lagu tersebut harmonis. Sama seperti musik, bangunan nantinya dibentuk dari garis garis yang akan digabungkan tersebut. Diagram tersebut lalu ditaruh ke dalam satu ruang kartesian di tapak dengan ukuran sumbu $x, y$ dan $z$ yang sudah disesuaikan dengan kondisi aslinya. Dengan penggabungan tersebut, terciptalah harmonisasi dari not - not yang sudah ditransformasikan. Garis - garis kemudian disatukan untuk membentuk bidang - bidang mengingat kaidah arsitektur yang bermula dari sebuah titik yang digabungkan menjadi garis, lalu digabungkan Kembali menjadi bidang, dan digabungkan lagi untuk menjadi ruang - ruang.
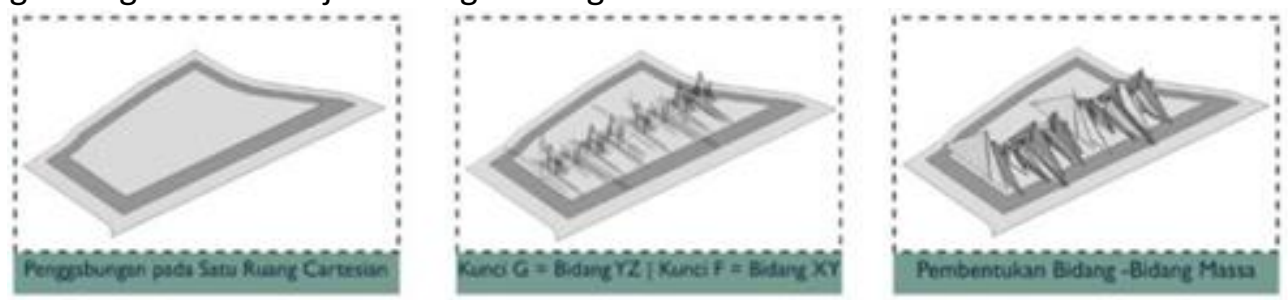

Gambar 4. Perubahan Diagram ke Bidang

Sumber : Penulis, 2020

Bidang - bidang tersebut disesuaikan kembali dengan zoning pada tapak, yang direncanakan sesuai dengan analisis kawasan. Mulai dari akses sampai program mulai diperhitungkan dalam zoning tersebut sehingga dapat terlihat pembagian ruangnya, dan diagram yang didapatkan dari lagu tadi akan dapat menyesuakan zonanya masing - masing.
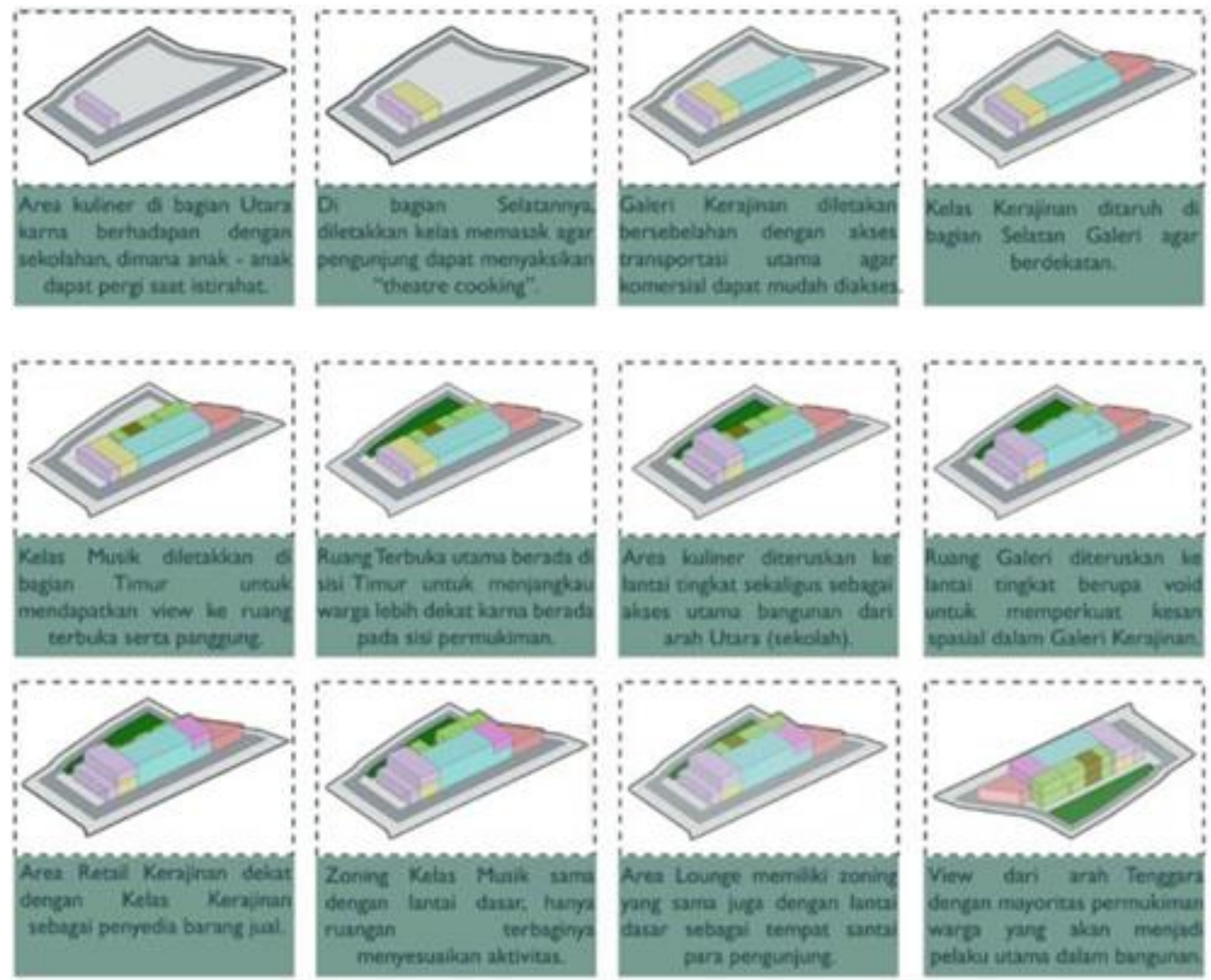

Gambar 5. Zoning

Sumber : Penulis, 2020 
Setelah zoning tercipta, bentuk yang tadi didapat dari not balok, digabungkan dengan bentuk yang didapatkan dari blok - blok zoning dan dilakukan penyesuaian agar menjadi sebuah gubahan dengan ruang - ruang fungsional di dalamnya. Selain zoning, ada pula penyesuaian lain seperti ruang gerak standar, sirkulasi, aktivitas yang sedikit demi sedikit mentransformasikan gubahannya menjadi bentuk yang dapat berfungsi dengan baik sebagai third place.
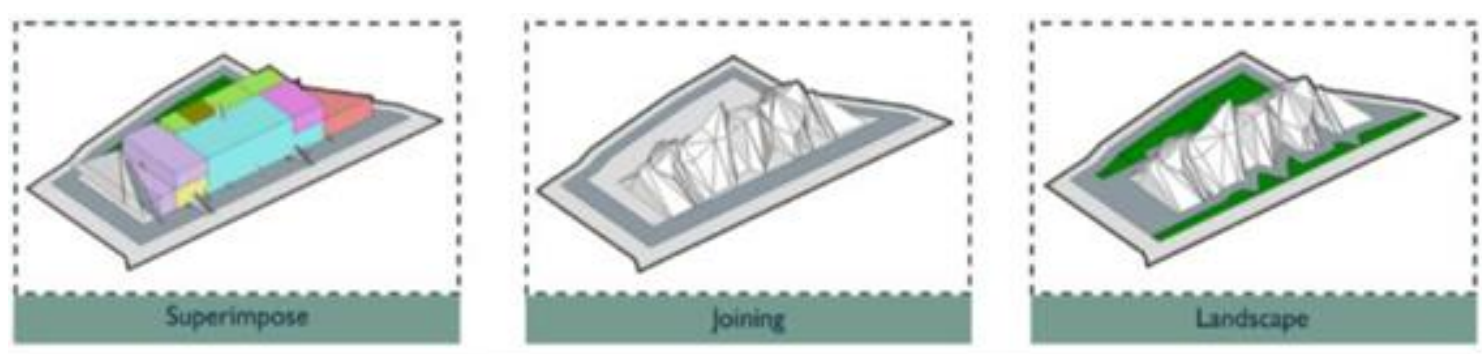

Gambar 6. Penyesuaian

Sumber : Penulis, 2020

Selanjutnya, penyesuaian bersifat lebih kecil ke dalam ruang - ruang yang ada. Dengan memperhatikan ruang gerak dan aktivitas manusia di dalamnya, ruang negatif pada massa akan berubah sedikit demi sedikit menyesuaikan standard yang didapatkan dari buku Time Saver Standards, Human Dimension dan Architect's Data.

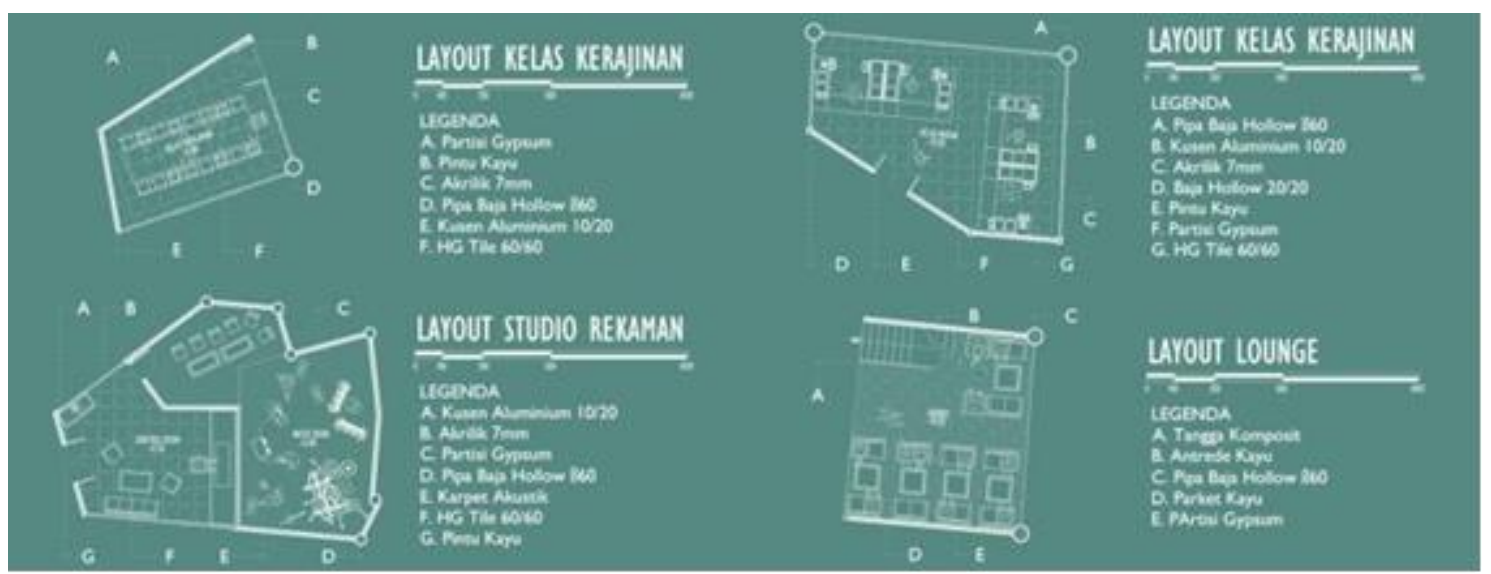

Gambar 7. Contoh Penyesuaian ke Dalam Ruang - Ruang

Sumber : Penulis, 2020

\section{KESIMPULAN DAN SARAN} Kesimpulan

Jadilah sebuah gubahan yang mewadahi program kuliner, musik dan kerajinan. Keseluruhan bangunannya mulai dari program hingga massa merepresentasikan sebuah third place yang cocok untuk kawasan Duri Utara dengan heterogenitasnya yang tinggi dan mempunya variasi program didalamnya. Bentuk bangunannya pun tidak kaku dan monoton, melainkan terlihat bermain yang merepresentasikan sebuah third place. Proses transformasinya didominasi oleh penyesuaian yang terus menerus karena ingin mempertahankan diagram awal yang didapat, tetapi juga dapat berfungsi dengan benar untuk aktivitas di dalamnya. Pada akhir tahap nantinya, aka nada pendetailan bentuk untuk mencapai karakter - karakter third place menurut Ray Oldenburg. 


\section{Saran}

Alangkah baiknya kalau sebuah third place hadir disetiap sudut kota dengan ciri khasnya masing - masing kawasan. Penting untuk sebuah third place tercipta dengan melihat kembali karakter kawasannya agar program yang diusulkan dapat tepat guna. Dengan haridnya third place di setiap kawasan, penduduk diharapkan dapat menjadi lebih terikat satu sama lain dan kebutuhan di tingkat ketiga mereka terpenuhi.

\section{DAFTAR PUSTAKA}

Alaahassan. (2014). 6 Most Popular Passions I've Noticed People Have. Diakses Januari 2020, dari https://www.alaahassan.com/2014/09/27/6-popular-passions-ive-noticed-people/ Kemendikbud RI. (2020). Kenapa Merdeka Belajar?. Jakarta: Indonesia Millenial Summit 2020 Inc. (2015). 7 Ways Successful People Spend Their Free Time. Diakses pada Februari 2020, dari https://www.inc.com/jayson-demers/7-ways-successful-people-spend-their-free-time.html Jormakka, K. (2003). Basic Design Methods. Vienna: Birkhäuser Architecture.

Maslow, A. H. (2019). A Theory of Human Motivation. New Delhi: General Press.

Oldenburg, R. (1989). The Great, Good Place. Boston: De Capo Press.

Pena, W. M. (2001). Problem Seeking: An Architectural Programming Primer. New York: John Willey \& Sons, Inc. 